\title{
Hydrogen Adsorption on Platinum-Gold Bimetallic Nanoparticles: A Density Functional Theory Study
}

\author{
Minmin Hu, ${ }^{\dagger}$ Douglas P. Linder, ${ }^{\ddagger}$ Marco Buongiorno Nardelli, ${ }^{\S}$ and Alberto Striolo $*, \dagger$ \\ ${ }^{\dagger}$ School of Chemical, Biological and Materials Engineering, The University of Oklahoma, Norman, Oklahoma 73019, United States \\ ${ }^{\ddagger}$ Department of Chemistry and Physics, Southwestern Oklahoma State University, Weatherford, Oklahoma 73098, United States \\ ${ }^{\S}$ Department of Physics, University of North Texas, Denton, Texas 76203, United States
}

\section{Supporting Information}

ABSTRACT: Using ab initio density functional theory, we investigate how hydrogen interacts with $\mathrm{Pt}-\mathrm{Au}$ bimetallic nanoparticles (NPs) of various compositions. Several Au, Pt, and $\mathrm{Pt}-\mathrm{Au}$ NPs of 85 atoms are considered. The results indicate that both the adsorption energy and the geometry of the most favorable adsorption sites are dependent on the local distribution of metal atoms. On some adsorption sites, our results suggest that the hydrogen adsorption on $\mathrm{Pt}-\mathrm{Au}$ NPs can be more favorable than that on monometallic Pt NPs of similar size. The results are interpreted with the aid of a number of electronic structure details, including d-band
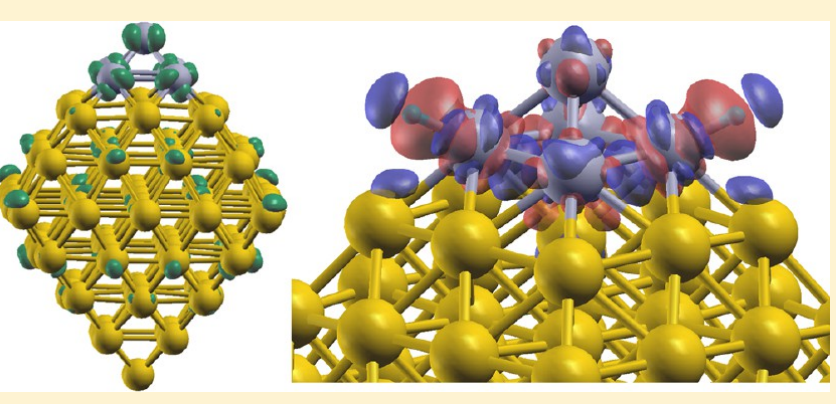
structure, density of states, electronic population, and charge density differences.

\section{INTRODUCTION}

Gold, the noblest of all metals, is not reactive in the bulk phase. ${ }^{1}$ However, Au nanoparticles (NPs) show catalytic properties for a wide range of reactions. ${ }^{2,3}$ Both NP size and shape affect the catalytic activity. ${ }^{4,5}$ Several possibilities have been proposed to explain the high catalytic activity of Au NPs, including the high density of atoms with low coordination number, inter- and intra-atomic charge redistributions.

$\mathrm{Au}$ NPs show remarkable performance for catalyzing hydrogenation reactions. $^{6-8}$ For example, Hugon et al. ${ }^{9}$ produced $100 \%$ butenes by the hydrogenation of 1,3-butadiene using supported Au NPs. Corma et al. ${ }^{10}$ found that Au NPs supported by $\mathrm{TiO}_{2}$ or $\mathrm{Fe}_{2} \mathrm{O}_{3}$ yield $>95 \%$ selectivity to cyclohexanone oxime from nitroarenes. However, the activity for hydrogenation reactions on Au catalysts is $\sim 2$ orders of magnitude lower compared to that of Pt-based catalysts. ${ }^{1,12}$ Hydrogen dissociation and adsorption are likely the ratelimiting steps in hydrogenation reactions catalyzed by $\mathrm{Au}$ NPs. ${ }^{13-16}$

Hydrogen adsorbed on isolated or supported Au NPs is occasionally studied by experiments. ${ }^{17}$ The amount of hydrogen adsorption over $\mathrm{Au}$ NPs increases as the temperature increases from 298 to $373 \mathrm{~K}$, indicating that hydrogen dissociation is an active process. ${ }^{18,19}$ Experimental evidence suggests that hydrogen is predominantly dissociated and adsorbed at corner and edge sites of $\mathrm{Au}$ NPs. ${ }^{19,20}$ These experiments are coupled by theoretical studies, which are usually conducted for very small NPs. ${ }^{21}$ For example, studying one NP of $13 \mathrm{Au}$ atoms on titania, Corma et al. ${ }^{22}$ found that hydrogen cannot be activated over positively charged Au. Barrio et al. ${ }^{23}$ suggested that ensemble effects and the presence of low coordinated $\mathrm{Au}$ atoms are both important factors for dissociating hydrogen on Au NPs.

Instead of Au-based catalysts, Pt catalysts are very often employed for hydrogenation reactions in the industry. ${ }^{24}$ According to experimental X-ray absorption near edge structure (XANES) data, hydrogen adsorbs on Pt top, bridge, and hollow sites. $^{25}$ It has been found that hydrogen dissociates at corner and edge sites, and then it diffuses to facet Pt sites. ${ }^{26,27}$ This is different compared to what happens on Au catalysts, where the $\mathrm{H}$ atoms cannot spill to the facet sites due to the closed shell electronic configuration of $\mathrm{Au}$ atoms. ${ }^{18,19}$ Theory suggests that increased catalytic activity over bulk $\mathrm{Pt}$ can be achieved using $\mathrm{Pt}$ NPs. ${ }^{26}$

The scope of the present manuscript is to understand whether bimetallic catalysts can take advantage of the properties of both $\mathrm{Pt}$ and $\mathrm{Au}$ nanocatalysts. Perhaps it will be possible to obtain nanocatalysts that are as active as $\mathrm{Pt}$ and as selective as $\mathrm{Au}$. As a first step, we focus here on hydrogen adsorption on several NPs, the first step of many hydrogenation reactions.

It is known that bimetallic NPs can provide higher selectivity, stability, and catalytic activity compared to monometallic catalysts. $^{28,29}$ Because $\mathrm{Pt}-\mathrm{Au} \mathrm{NPs}$ can catalyze oxidation reactions at mild temperatures, most research is concerned with their application in proton-exchange membrane fuel cells (PEMFCs), ${ }^{30}$ methanol oxidation fuel cells (DMFCs), ${ }^{31}$ direct formic acid fuel cells (DFAFCs), ${ }^{32,33}$ etc. $\mathrm{Xu}$ et al. ${ }^{34}$ pointed

Received: December 21, 2012

Revised: June 20, 2013

Published: June 24, 2013 
out that the presence of $\mathrm{Au}$ could reduce $\mathrm{CO}$ poisoning, leading to a higher utilization of the Pt catalyst. Single atom alloys have received much attention toward catalyzing hydrogenation reactions. Kyriakou et al. ${ }^{35}$ demonstrated that adding isolated $\mathrm{Pd}$ atoms to a $\mathrm{Cu}$ surface lowers the energy barrier for both hydrogen dissociation and desorption, yielding a very efficient catalyst for the hydrogenation of styrene and acetylene. Jiang et al. suggested that widely dispersed $\mathrm{Ag}$ on supported $\mathrm{Pd}$ NPs could greatly enhance activity for 4-nitrophenol hydrogenation, ${ }^{36}$ while $\mathrm{Ag}$ acts as a promoter that provides selectivity. ${ }^{37}$ Some results suggest that synergism between $\mathrm{Pt}$ and $\mathrm{Au}$ might enable $\mathrm{Pt}-\mathrm{Au}$ bimetallic NPs to be more active than monometallic Au NPs for hydrogenation of multifunctional compounds. Serna et al., ${ }^{16}$ e.g., found that substituting a small amount of $\mathrm{Pt}$ onto titania-supported $\mathrm{Au}$, could increase the catalytic activity by 1 order of magnitude for the hydrogenation of nitro aromatics. Unfortunately, such small amounts of $\mathrm{Pt}$ in Au catalyst are hard to be fully characterized experimentally. Sun et al. ${ }^{15}$ and Hong et al. ${ }^{38}$ conducted experiments to assess the catalytic activity of $\mathrm{Pt}$ on $\mathrm{Au}$ catalyst with different $\mathrm{Pt} / \mathrm{Au}$ ratios toward the hydrogenation of cinnamaldehyde. The results suggested that fully dispersed $\mathrm{Pt}$ atoms act as active sites for hydrogen dissociation and adsorption. These authors highlighted the need of better understanding the details of how hydrogen interacts with PtAu NPs.

To achieve such an understanding, theoretical studies of hydrogen adsorption on $\mathrm{Pt}-\mathrm{Au} \mathrm{NPs}$ could be useful. A few such investigations exist in the literature. For example, a DFT calculation indicates that on $\mathrm{Pt}-\mathrm{Au}$ NPs supported by titania, $\mathrm{Pt}$ atoms could reduce the energy barrier encountered in hydrogen dissociation. ${ }^{39}$ The electronic details of such phenomena remain unknown. An experimental study performed by Bus et al. ${ }^{20}$ indicates that the amount of hydrogen adsorbed per unit surface area is lower on $\mathrm{Pt}-\mathrm{Au}$ NPs than on Pt NPs of similar size, although, based on XANES data, hydrogen interacts with both $\mathrm{Au}$ and $\mathrm{Pt}$ atoms.

Before discussing the systems studied in this work it is important to remember that bulk $\mathrm{Au}$ and $\mathrm{Pt}$ metals are immiscible for a large range of compositions. ${ }^{40}$ A DFT calculation indicates that $\mathrm{Au}$ atoms segregate to the $\mathrm{Pt}$ (111) surface. ${ }^{47} \mathrm{Pt}-\mathrm{Au}$ NPs show physical properties different from their bulk counterparts. ${ }^{41} \mathrm{Pt}-\mathrm{Au}$ single-phase alloys, partial alloys, hetero aggregates, and core-shell NPs can be prepared. ${ }^{31,42-45}$ The alloy structure of $\mathrm{Pt}-\mathrm{Au}$ NPs supported by silica can be preserved at $700{ }^{\circ} \mathrm{C} .{ }^{46}$ Fully dispersed $\mathrm{Pt}$ ensembles on Au NPs can also be synthesized by reductive deposition, ${ }^{38}$ or by the impregnation (IMP) method. ${ }^{16} \mathrm{~A}$ number of theoretical ${ }^{47-49}$ and experimental ${ }^{50}$ studies suggest that $\mathrm{Au}$ tends to segregate on the surface of the $\mathrm{Pt}-\mathrm{Au} \mathrm{NPs}$, and that the Au-shell Pt-core structure is the most thermodynamically favorable. ${ }^{51}$

In the present study, we investigate the interaction of $\mathrm{Pt}, \mathrm{Au}$, and $\mathrm{Pt}-\mathrm{Au} \mathrm{NPs}$ with hydrogen atoms using ab initio density functional theory (DFT). We report the most favorable adsorption sites and the adsorption energy on several $\mathrm{Pt}-\mathrm{Au}$ NPs. The effects of the local atomic distribution are evaluated quantitatively. We find that it is possible to control the adsorption strength of hydrogen on $\mathrm{Pt}-\mathrm{Au}$ bimetallic NPs, and hence, presumably, its surface distribution. A combination of ensemble and electronic effects could explain the results. Moreover, $\mathrm{Pt}-\mathrm{Au}$ NPs with the same composition yield different hydrogen adsorption energy and preferential sites depending on their atomic distribution. These results are qualitatively consistent with experimental observations. ${ }^{15,20,45}$ To explain our results, density of states, electronic population of relevant atoms, highest occupied molecular orbital (HOMO), and charge density differences are computed. Since to interpret catalytic activity results for transition metal catalysts, structure and position of the d-band is often invoked, ${ }^{52,53}$ we detail the d-band center in our $\mathrm{Pt}-\mathrm{Au}$ bimetallic NPs.

In the remainder of this manuscript, we first present the computation details, then we analyze the NPs geometry and the hydrogen adsorption energy; finally, we characterize the electronic structure of the NPs. We conclude by summarizing our most important observations.

\section{COMPUTATIONAL DETAILS AND METHODS}

Hydrogen adsorption on monometallic $\mathrm{Au}$ and $\mathrm{Pt}$, and on bimetallic $\mathrm{Pt}-\mathrm{Au}$ NPs is studied with the periodic supercell model. One isolated 85 -atom NP is placed in a $45 \times 45 \times 45 \AA$ cubic cell. The size of the cubic cell is large enough that the distance between the closest atoms belonging to neighboring images is never lower than $20 \AA$ in all directions. The initial structures of the metal NPs are based on previous studies, which will be discussed below. The NPs are initially constructed using the software XCrySDen. ${ }^{54}$ The positions of all atoms are fully relaxed without imposing any symmetric constraints.

The unique physical and chemical properties of nanostructured catalysts are known to be strongly related to their size. ${ }^{4,55}$ In the present work we used $\mathrm{Pt}, \mathrm{Au}$, or bimetallic $\mathrm{Pt}-$ $\mathrm{Au}$ NPs of size $\sim 1.5 \mathrm{~nm}$ ( 85 atoms), large enough that they could be prepared and studied experimentally. ${ }^{20,56}$ The objective of this paper is not to find the stable structure of the $\mathrm{Pt}-\mathrm{Au}$ bimetallic NP, but instead to quantify the effect of local composition and atomic distribution on hydrogen adsorption and dissociation. The results might depend on the atomic structural arrangement within the NPs. Based on a literature review, ${ }^{57-62}$ we concluded that the octahedral structure should be stable for 85-atoms NPs and will allow us to satisfactorily compare results obtained on different NPs.

Because one hydrogen atom is much smaller in size than each of the 85-atoms NPs and because the octahedral NP structure is symmetric, we evaluated hydrogen adsorption only on the three atomic layers on one vertex of each NP. Bimetallic NPs are prepared by changing the atomic composition of these layers: (a) when the first layer (vertex atom) of the monometallic NPs $\left(\mathrm{Pt}_{85}\right.$ or $\left.\mathrm{Au}_{85}\right)$ is replaced by the second element, $\mathrm{Au}_{84} \mathrm{Pt}_{1}-\mathrm{t}$ and $\mathrm{Pt}_{84} \mathrm{Au}_{1}$ - $\mathrm{NPs}$ are generated; (b) when the entire second layer is substituted, $\mathrm{Au}_{81} \mathrm{Pt}_{4}$ and $\mathrm{Pt}_{81} \mathrm{Au}_{4} \mathrm{NPs}$ are built; (c) when both the whole first and the second layers are replaced, $\mathrm{Pt}_{80} \mathrm{Au}_{5}$ and $\mathrm{Au}_{80} \mathrm{Pt}_{5}$ NPs are obtained; (d) when only the center atom of the third layer is replaced, $\mathrm{Au}_{84} \mathrm{Pt}_{1}$-c and $\mathrm{Pt}_{84} \mathrm{Au}_{1}$-c NPs are obtained. Note that in our notation, the first metal in the bimetallic NPs is the one with more atoms present in the particle.

In each NP, the vertex atoms have the lowest coordination number, followed by edge atoms, atoms in the second layers, surface atoms, etc. Specifically, the vertex atoms in $\mathrm{Au}_{84} \mathrm{Pt}_{1}-\mathrm{t}$ and $\mathrm{Pt}_{84} \mathrm{Au}_{1}-\mathrm{t}$ NPs have four nearest neighbors, second layer atoms in $\mathrm{Au}_{81} \mathrm{Pt}_{4}$ and $\mathrm{Pt}_{81} \mathrm{Au}_{4} \mathrm{NPs}$ have seven nearest neighbors and are all in edge positions, etc.

$\mathrm{Au}_{84} \mathrm{Pt}_{1}-\mathrm{c}$ and $\mathrm{Pt}_{84} \mathrm{Au}_{1}-\mathrm{c}$ NPs are an approximation for coreshell structures. $\mathrm{Pt}_{80} \mathrm{Au}_{5}$ and $\mathrm{Au}_{80} \mathrm{Pt}_{5} \mathrm{NPs}$ have been prepared 
because they allow us to study the interaction between one hydrogen atom and the same metal atom types, but on bridge vs hollow sites, and to compare the results to those obtained on $\mathrm{Au}_{85}$ and $\mathrm{Pt}_{85} \mathrm{NPs}$. The effect of completely surrounding one atom with atoms of a different metal has been quantified by adsorbing hydrogen on $\mathrm{Au}_{84} \mathrm{Pt}_{1}-\mathrm{t}$ and $\mathrm{Pt}_{84} \mathrm{Au}_{1}-\mathrm{t} \mathrm{NPs}$. For completeness, we have also replaced all the vertex atoms in one $\mathrm{NP}$, obtaining $\mathrm{Au}_{79} \mathrm{Pt}_{6}$ and $\mathrm{Pt}_{79} \mathrm{Au}_{6} \mathrm{NPs}$. No obvious difference was observed between the data obtained on such NPs and those obtained on $\mathrm{Au}_{84} \mathrm{Pt}_{1}-\mathrm{t}$ and $\mathrm{Pt}_{84} \mathrm{Au}_{1}-\mathrm{t} \mathrm{NPs}$, as discussed in the Supporting Information.

The ab initio DFT calculations are performed using the Quantum-ESPRESSO package. ${ }^{63}$ The generalized-gradient approximation (GGA) exchange-correlation functional proposed by Perdew, Burke and Ernzerhof $(\mathrm{PBE})^{64}$ is employed. The wave functions and the charge density are expanded with kinetic cutoffs of 30 and 300 Ry, respectively. Electron-ion interactions are described using ultrasoft pseudopotentials. ${ }^{65,66}$ The following atomic configurations are obtained: $\mathrm{Pt}[\mathrm{Xe}]$ $4 \mathrm{f}^{14} 5 \mathrm{~d}^{9} 6 \mathrm{~s}^{1}$, Au $[\mathrm{Xe}] 4 \mathrm{f}^{14} 5 \mathrm{~d}^{9.5} 6 \mathrm{~s}^{1} 6 \mathrm{p}^{0.5}$, and $\mathrm{H} 1 \mathrm{~s}^{1}$. All the properties of the system are evaluated at the $\Gamma$ point of the Brillouin zone. The total energy is converged to within $1 \times$ $10^{-4} \mathrm{Ry}$, and the geometry is optimized until the atomic force is less than $1 \times 10^{-3} \mathrm{Ry} / \mathrm{bohr}$. To test the structure sensitivity of the results, we changed the optimal bond distances between adsorbed hydrogen and metal atoms by $\pm 0.10 \AA$ to create alternative configurations. The same final geometries and total energies were obtained after optimization.

Two hydrogen atoms were considered simultaneously. Because of the small size of the NPs simulated, it was often difficult to simultaneously adsorb two hydrogen atoms on similar adsorption sites found on the same facet. To obtain consistent results, we instead placed the two hydrogen atoms on the same type of adsorption sites, but on sites that are symmetric across the NPs. Explicitly, to calculate the hydrogen adsorption energy of the $\mathrm{H} 2$ site on $\mathrm{Pt}_{85}$, (see Figure $2 \mathrm{c}$ ) we placed one $\mathrm{H}$ atom on the $\mathrm{H} 2$ site at front facet, and another $\mathrm{H}$ atom on the $\mathrm{H} 2$ site available on the facet on the back of the NP. There is only one exception to this procedure: the adsorption studied on the T1 top site, in which case two $\mathrm{H}$ atoms were simultaneously placed on the vertex atom. For comparison, we also studied the adsorption of one single hydrogen atom on the T1 top site. We report results for the adsorption energy and H-metal bond length in Table 1, but these results are not included in the main part of the discussion.

The adsorption energy of hydrogen on a metal NP is calculated as

$$
E_{\text {Adsorption }}=E_{\mathrm{NP}+2 \mathrm{H}}-E_{\mathrm{NP}}-E_{\mathrm{H}_{2}}
$$

In eq $1, E_{\mathrm{NP}+2 \mathrm{H}}$ is the potential energy of $\mathrm{NP}$ with two hydrogen atoms adsorbed. $E_{\mathrm{NP}}$ is the potential energy of the isolated $\mathrm{NP}$ after geometry optimization. $E_{\mathrm{H}_{2}}$ is the potential energy of an isolated hydrogen molecule. The more negative $E_{\text {Adsorption, }}$ the stronger the adsorption. ${ }^{39}$

With similar spirit, charge density differences are evaluated using the formula

$$
\Delta \rho=\rho_{\mathrm{NP}+2 \mathrm{H}}-\rho_{\mathrm{NP}}-\rho_{2 \mathrm{H}}
$$

In eq $2, \rho_{\mathrm{NP}+2 \mathrm{H}}$ is the charge density of the NP with two hydrogen atoms adsorbed, $\rho_{\mathrm{NP}}$ is the charge density of isolated $\mathrm{NP}$, and $\rho_{2 \mathrm{H}}$ is the charge density of two isolated $\mathrm{H}$ atoms, with atomic positions frozen at the optimized geometry. ${ }^{67}$
Table 1. Adsorption Energy for Hydrogen on the Top Sites

\begin{tabular}{|c|c|c|c|c|c|c|}
\hline \multirow[b]{2}{*}{ NPs } & \multicolumn{5}{|c|}{ adsorption energy $[\mathrm{kcal} / \mathrm{mol}]$} & \multirow{2}{*}{$\frac{\begin{array}{c}\text { H-metal } \\
(\AA)\end{array}}{\mathrm{T} 1(\mathrm{H})}$} \\
\hline & $\mathrm{T} 1$ & $\mathrm{~T} 2$ & $\mathrm{~T} 3$ & $\mathrm{~T} 4$ & $\mathrm{~T} 1(\mathrm{H})$ & \\
\hline $\mathrm{Au}_{85}$ & - & - & - & - & - & - \\
\hline $\mathrm{Au}_{84} \mathrm{Pt}_{1}-\mathrm{t}$ & -15.82 & - & - & - & -7.62 & 1.581 \\
\hline $\mathrm{Au}_{84} \mathrm{Pt}_{1}-\mathrm{c}$ & - & - & - & - & - & - \\
\hline $\mathrm{Au}_{81} \mathrm{Pt}_{4}$ & - & -24.64 & - & - & - & - \\
\hline $\mathrm{Au}_{80} \mathrm{Pt}_{5}$ & -13.82 & -24.72 & - & - & -7.26 & 1.577 \\
\hline $\mathrm{Pt}_{85}$ & -10.87 & -18.79 & -13.06 & -20.88 & -6.39 & 1.584 \\
\hline $\mathrm{Pt}_{84} \mathrm{Au}_{1}-\mathrm{t}$ & - & -19.52 & -14.84 & -20.98 & - & - \\
\hline $\mathrm{Pt}_{84} \mathrm{Au}_{1}-\mathrm{c}$ & -10.35 & - & - & -19.13 & -7.13 & 1.584 \\
\hline $\mathrm{Pt}_{81} \mathrm{Au}_{4}$ & -13.99 & - & -15.93 & -18.21 & -7.30 & 1.570 \\
\hline $\mathrm{Pt}_{80} \mathrm{Au}_{5}$ & - & - & -16.12 & -18.49 & - & - \\
\hline
\end{tabular}
of $\mathrm{Au}, \mathrm{Pt}$, and $\mathrm{Pt}-\mathrm{Au} \mathrm{NPs}{ }^{a}$

a "- indicates that the adsorption is not favorable on the corresponding site. Data are expressed in $[\mathrm{kcal} / \mathrm{mol}]$. $\mathrm{T} 1(\mathrm{H})$ is for one hydrogen atom on the $\mathrm{T} 1$ site of $\mathrm{Au}, \mathrm{Pt}$, and $\mathrm{Pt}-\mathrm{Au}$ NPs. H-Metal is the bond distance between adsorbed hydrogen atom and the $\mathrm{Pt}$ atoms on T1 site. Distances are expressed in $\AA$.

The population distribution for metal atoms and $\mathrm{H}$ atoms is estimated by using the Löwdin orthogonalized basis. ${ }^{68}$

\section{RESULTS}

Optimized Geometries of Pt-Au Bimetallic NPs. The optimized geometries of the $10 \mathrm{NPs}$ studied are shown in Figure 1. Structure-sensitivity analysis was performed by changing the metal-metal bond by $\pm 0.05 \AA$ to create alternative initial configurations. All the NPs used here were found to be stable. Among the eight bimetallic NPs shown in Figure 1, there are two groups of homotops, which are $\mathrm{Au}_{84} \mathrm{Pt}_{1}$ and $\mathrm{Pt}_{84} \mathrm{Au}_{1} \mathrm{NPs}$. In these NPs, the single $\mathrm{Pt}$ or $\mathrm{Au}$ atom is located in the interior or the exterior of the NPs. We found that $\mathrm{Au}_{84} \mathrm{Pt}_{1}-\mathrm{c}$ is $11.50 \mathrm{kcal} / \mathrm{mol}$ more stable than $\mathrm{Au}_{84} \mathrm{Pt}_{1}-\mathrm{t}$. On the other hand, $\mathrm{Pt}_{84} \mathrm{Au}_{1}$ - $\mathrm{t}$ is $19.45 \mathrm{kcal} / \mathrm{mol}$ more stable than $\mathrm{Pt}_{84} \mathrm{Au}_{1}$-c. These results indicate that $\mathrm{Au}$ resides preferentially on the outer shell, and $\mathrm{Pt}$ in the core, in agreement with previous theoretical ${ }^{48,69-71}$ and experimental ${ }^{56,72,73}$ studies. This was expected, because the atomic radius of $\mathrm{Au}(1.44 \AA)$ is larger than that of $\mathrm{Pt}(1.39 \AA)^{74}$ and the surface energy of $\mathrm{Au}$ is lower than that of $\mathrm{Pt}^{75}$

Hydrogen Adsorption. Hydrogen adsorption is evaluated on the top three atomic layers of each NP. Fifteen possible adsorption sites have been identified, which are shown in Figure 2: four top sites, six bridge sites, and two hollow sites. Among the four top sites, three (T1, T2, and T3) are located on the edge atoms of NPs, the fourth (T4) is located on the NPs facet. Out of the bridge sites, B1 and B4 are located on the NPs edge; B2, B3, B5, and B6 are located on the NPs facet. The hollow site is known to be the most favorable site for hydrogen adsorption on the bulk Pt surface. Two kinds of hollow sites are available on our NPs: three hexagonal close packed (hcp) (H1, $\mathrm{H} 3$, and $\mathrm{H} 5$ ) and two face-centered cubic (fcc) ( $\mathrm{H} 2$ and $\mathrm{H} 4)$. As mentioned in the Computation Details and Methods section, two hydrogen atoms are adsorbed simultaneously on each NP. Several stable sites were identified after geometry optimization (see Figure 3 ). The corresponding adsorption energies are reported in Tables 1,2 , and 3 .

Based on our calculations, the most favorable adsorption site for hydrogen is the $\mathrm{B} 4$ site on $\mathrm{Pt}_{84} \mathrm{Au}_{1}$-c $(-29.39 \mathrm{kcal} / \mathrm{mol})$, and the weakest one is the $\mathrm{B} 4$ site on $\mathrm{Au}_{85}(-1.53 \mathrm{kcal} / \mathrm{mol})$. 

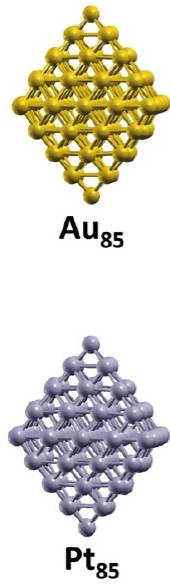

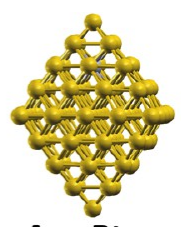

$\mathrm{Au}_{84} \mathrm{Pt}_{1}-\mathrm{C}$

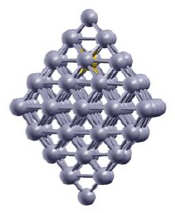

$\mathrm{Pt}_{84} \mathrm{Au}_{1}-\mathrm{C}$

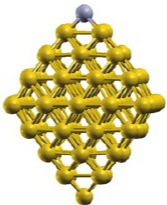

$\mathrm{Au}_{84} \mathrm{Pt}_{1}-\mathrm{t}$

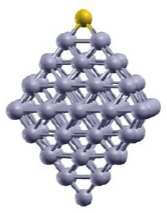

$\mathrm{Pt}_{84} \mathrm{Au}_{1}-\mathrm{t}$

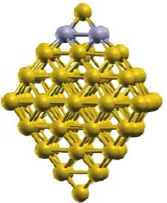

$\mathrm{Au}_{81} \mathrm{Pt}_{4}$

$\mathrm{Au}_{80} \mathrm{Pt}_{5}$
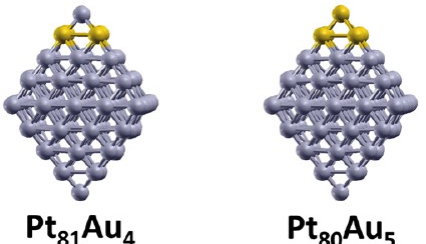

Figure 1. (Top) Optimized geometries of Au-based 85-atom NPs. (Bottom) Optimized geometries of Pt-based 85-atom NPs. The Pt and Au atoms are represented by ice blue and yellow spheres, respectively. The notation ' $t$ ' indicates that the replaced atom is in the vertex of the NPs (e.g., Au in $\mathrm{Pt}_{84} \mathrm{Au}_{1}-\mathrm{t}$ ), while '-c' indicates that the replaced atom is in the center of the $3 \mathrm{rd}$ layer of the NPs (e.g., $\mathrm{Au}$ in $\left.\mathrm{Pt}_{84} \mathrm{Au}_{1}-\mathrm{c}\right)$.
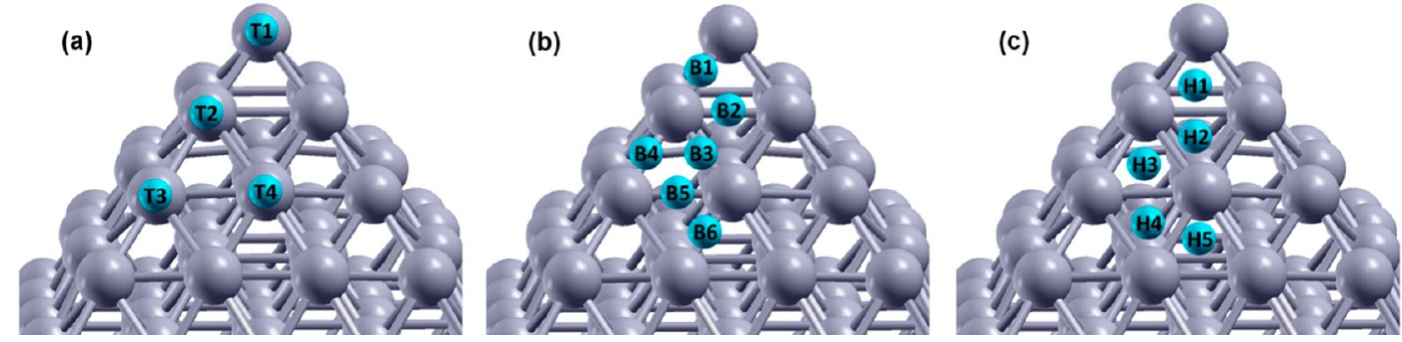

Figure 2. Possible adsorption sites for hydrogen atoms on the top three atomic layers of the $\mathrm{Pt}_{85} \mathrm{NP}$. (a) Top sites. (b) Bridge sites. (c) Hollow sites.
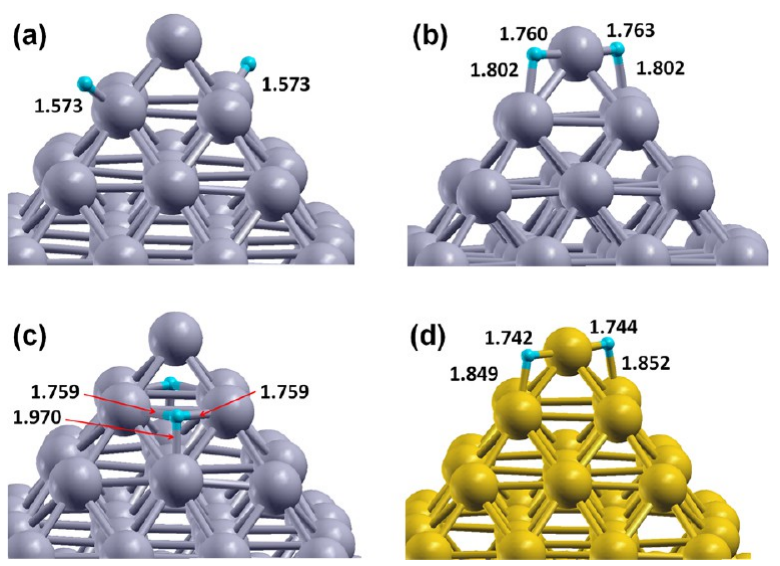

Figure 3. Optimized geometries for hydrogen atoms adsorbed on monometallic Pt and Au NPs. (a) Hydrogen atoms adsorbed on the T2 site of the $\mathrm{Pt}_{85} \mathrm{NP}$. (b) Hydrogen atoms adsorbed on the B1 site of the $\mathrm{Pt}_{85}$ NP. (c) Hydrogen atoms adsorbed on the $\mathrm{H} 2$ site of $\mathrm{Pt}_{85} \mathrm{NP}$. (d) Hydrogen atoms adsorbed on the $\mathrm{B} 1$ site of $\mathrm{Au}_{85} \mathrm{NP}$. Distances are in $\AA$.

Generally, the most favorable adsorption site on the monometallic NPs $\left(\mathrm{Au}_{85}\right.$ and $\left.\mathrm{Pt}_{85}\right)$ is located at the bridge sites at the edge of NPs. On bimetallic NPs, the most favorable adsorption site depends on the atomic distributions. The adsorption sites located on the facets show weaker adsorption compared to the sites at edge or corner sites, perhaps not surprisingly. Dissociated $\mathrm{H}$ atoms could interact favorably with both $\mathrm{Au}$ and $\mathrm{Pt}$ atoms on bridge sites. On the contrary, the top and hollow sites are favorable when $\mathrm{H}$ atoms only interact with $\mathrm{Pt}$ atoms. When hydrogen interacts only with $\mathrm{Au}$, only the
Table 2. Adsorption Energy for Hydrogen on the Bridge Sites of $\mathrm{Au}, \mathrm{Pt}$, and $\mathrm{Pt}-\mathrm{Au} \mathrm{NPs}^{a}$

\begin{tabular}{lcccccc} 
& \multicolumn{7}{c}{ adsorption energy [kcal/mol] } \\
\cline { 2 - 7 } \multicolumn{1}{c}{$\mathrm{NPs}_{4}$} & $\mathrm{~B} 1$ & $\mathrm{~B} 2$ & $\mathrm{~B} 3$ & $\mathrm{~B} 4$ & $\mathrm{~B} 5$ & $\mathrm{~B} 6$ \\
$\mathrm{Au}_{85}$ & -4.24 & - & - & -1.53 & - & - \\
$\mathrm{Au}_{84} \mathrm{Pt}_{1}-\mathrm{t}$ & -21.29 & - & - & -9.97 & - & - \\
$\mathrm{Au}_{84} \mathrm{Pt}_{1}-\mathrm{c}$ & -5.24 & - & - & -4.26 & - & - \\
$\mathrm{Au}_{81} \mathrm{Pt}_{4}$ & -17.19 & -16.23 & - & - & - & - \\
$\mathrm{Au}_{80} \mathrm{Pt}_{5}$ & -26.35 & -10.36 & - & - & - & - \\
$\mathrm{Pt}_{85}$ & -23.13 & - & - & -27.65 & - & -17.43 \\
$\mathrm{Pt}_{84} \mathrm{Au}_{1}-\mathrm{t}$ & -14.31 & - & -17.05 & -27.33 & - & -18.10 \\
$\mathrm{Pt}_{84} \mathrm{Au}_{1}-\mathrm{c}$ & -23.68 & -8.20 & - & -29.39 & - & -16.93 \\
$\mathrm{Pt}_{81} \mathrm{Au}_{4}$ & -21.98 & - & - & -17.56 & -14.27 & - \\
$\mathrm{Pt}_{80} \mathrm{Au}_{5}$ & -5.83 & - & - & -14.96 & - & -
\end{tabular}

a"- indicates that the adsorption is not favorable on the corresponding site. Data are expressed in $[\mathrm{kcal} / \mathrm{mol}]$.

bridge sites are found to be favorable for adsorption. More details are discussed in what follows.

3.1.1. Hydrogen Adsorption on Monometallic Au and Pt NPs. Hydrogen only adsorbs favorably on the B1 and B4 sites of the monometallic Au NP, but with relatively weak adsorption energies (see Figure 3d). The adsorption energy is stronger on B1 than on B4. Bus et al. ${ }^{19,20}$ studied experimentally hydrogen dissociation and adsorption on Au NPs of size 1.1-1.4 nm, supported by silica and alumina. The results were consistent with hydrogen dissociation and adsorption at corner and edge sites of $\mathrm{Au} \mathrm{NPs,} \mathrm{in} \mathrm{qualitative} \mathrm{agreement} \mathrm{with} \mathrm{our} \mathrm{results.}$ Theoretical results also suggest that the neutral $\mathrm{Au}$ atoms at corner and edge sites are the active sites for hydrogen 
Table 3. Adsorption Energy for Hydrogen on the Hollow Sites of $\mathrm{Au}, \mathrm{Pt}$, and $\mathrm{Pt}-\mathrm{Au} \mathrm{NPs}{ }^{a}$

\begin{tabular}{lccccc} 
& \multicolumn{5}{c}{ adsorption energy $[\mathrm{kcal} / \mathrm{mol}]$} \\
\cline { 2 - 6 } $\mathrm{NPs}$ & $\mathrm{H} 1$ & $\mathrm{H} 2$ & $\mathrm{H} 3$ & $\mathrm{H} 4$ & $\mathrm{H} 5$ \\
$\mathrm{Au}_{85}$ & - & - & - & - & - \\
$\mathrm{Au}_{84} \mathrm{Pt}_{1}-\mathrm{t}$ & - & - & - & - & - \\
$\mathrm{Au}_{84} \mathrm{Pt}_{1}-\mathrm{c}$ & - & - & - & - & - \\
$\mathrm{Au}_{81} \mathrm{Pt}_{4}$ & - & - & - & - & - \\
$\mathrm{Au}_{80} \mathrm{Pt}_{5}$ & -13.44 & - & - & - & - \\
$\mathrm{Pt}_{85}$ & -12.46 & -10.78 & - & - & -18.30 \\
$\mathrm{Pt}_{84} \mathrm{Au}_{1}-\mathrm{t}$ & - & -13.96 & - & - & -18.56 \\
$\mathrm{Pt}_{84} \mathrm{Au}_{1}-\mathrm{c}$ & -12.91 & -11.31 & - & - & -18.03 \\
$\mathrm{Pt}_{81} \mathrm{Au}_{4}$ & - & - & - & -14.43 & - \\
$\mathrm{Pt}_{80} \mathrm{Au}_{5}$ & - & - & - & -14.31 & - \\
a“" & indicates & that the & adsorption is not favorable & on the \\
corresponding site. Data are expressed in [kcal/mol]. & \\
\hline
\end{tabular}

dissociation. $^{22,23}$ In qualitative agreement with our results, Boronat et al. ${ }^{39}$ reported an adsorption energy of $-5.80 \mathrm{kcal} /$ mol for hydrogen on $\mathrm{a} \mathrm{Au}_{38} \mathrm{NP}$ supported by titania. DFT calculations for hydrogen adsorbed on unsupported Au clusters of 2 or 3 atoms yield adsorption energies of $-5.76 \mathrm{kcal} / \mathrm{mol}$ with the B3LYP functional, ${ }^{76}$ and $-4.68 \mathrm{kcal} / \mathrm{mol}$ with the RPBE functional. ${ }^{23} \mathrm{H}-\mathrm{Au}$ distances of $1.723 \AA$ and $1.826 \AA^{39}$ for $\mathrm{H}$ on the bridge site of $\mathrm{Au}_{38} \mathrm{NPs}$, and $1.760 \AA$ for $\mathrm{H}$ on $\mathrm{Au}_{6}$ $\mathrm{NPs}^{76}$ have been reported.

Hydrogen atoms can adsorb on both facet sites and lowcoordinated sites (corner and edge) on $\mathrm{Pt}_{85}$. As expected, the adsorption energy is much stronger (more negative) compared to that found on $\mathrm{Au}_{85}$. The bridge and edge sites are the most favorable for hydrogen adsorption on $\mathrm{Pt}_{85}$. These results are consistent with the DFT calculations presented by Okamoto, ${ }^{55}$ who reported that the strongest adsorbed hydrogen atom on $\mathrm{Pt}_{55}$ NPs is found at the bridge site at the edge $(-34.5 \mathrm{kcal} /$ $\mathrm{mol})$, followed by that found at the top $(-30.8 \mathrm{kcal} / \mathrm{mol})$ and hollow sites $(-19.8 \mathrm{kcal} / \mathrm{mol})$. Okamoto also showed that hydrogen adsorption on $\mathrm{Pt}_{55}$ and $\mathrm{Pt}_{150}$ NPs hollow sites is energetically less favorable than that on the bulk Pt fcc (111). An adsorption energy of $-22.40 \mathrm{kcal} / \mathrm{mol}$ was reported for hydrogen adsorption on $\mathrm{Pt}_{3} .{ }^{77}$ Experimental data are available for hydrogen adsorption on Pt NPs supported by $\mathrm{NaY}$ zeolite (adsorption energy of $-31.34 \mathrm{kcal} / \mathrm{mol})^{78}$ and on the bulk $\mathrm{Pt}$ (111) surface (from -16.13 to $-19.13 \mathrm{kcal} / \mathrm{mol}$ ). ${ }^{79-81}$ These data are in good agreement with our findings.

The optimized geometries of the $\mathrm{Pt}_{85}$ NPs after hydrogen adsorption are shown in Figure $3 a-c$, where we also report the $\mathrm{H}-\mathrm{Pt}$ bond distance. These are in good agreement with previous DFT calculations $(\mathrm{H}-\mathrm{Pt}$ distances of $1.53 \AA$ on the top site of a Pt trimer, ${ }^{77}$ and $1.77 \AA$ on the bridge site of a $\mathrm{Pt}_{13}$ $\mathrm{NP}^{78}$ have been reported).

Returning to our results, we found that the adsorption energy of one hydrogen atom on T1 (see Table 1) is more negative than half the adsorption energy of two $\mathrm{H}$ atoms on the same site. This suggests that the two $\mathrm{H}$ atoms adsorbed simultaneously on the $\mathrm{T} 1$ site strongly interact with each other, perhaps as expected given the short distance that separates the two adsorbed atoms.

3.1.2. Hydrogen Adsorption on Pt-Au Bimetallic NPs. When the second metal is added to the monometallic NPs, several different local environments are available for hydrogen adsorption. Adsorption energies obtained in our calculations are reported in Tables 1, 2, and 3. Our results suggest that both
$\mathrm{Au}$ and $\mathrm{Pt}$ activity toward hydrogen adsorption become stronger in the bimetallic NPs compared with their monometallic NPs, although hydrogen atoms show a preference for Pt atoms also in bimetallic NPs. The influence of $\mathrm{Au}$ in determining the catalytic activity of $\mathrm{Pt}-\mathrm{Au}$ NPs has traditionally been attributed to ensemble effects. ${ }^{82,83}$ However, in some circumstances our results show that hydrogen atoms could also interact with $\mathrm{Au}$ atoms, suggesting that other effects might also be important. For instance, the $\mathrm{B} 1$ site of $\mathrm{Au}_{84} \mathrm{Pt}_{1}-\mathrm{t}$ and $\mathrm{Pt}_{81} \mathrm{Au}_{4}$, where hydrogen interacts with both $\mathrm{Au}$ and $\mathrm{Pt}$ atoms, are found to be very favorable.

By comparing the hydrogen adsorption on the same site in different NPs, we confirmed that in bimetallic NPs Au and Pt atoms influence each other. The T2 site is a good example, since hydrogen atoms directly adsorb on its proximity (see Table 1). We found that when the number of neighboring $\mathrm{Au}$ atoms increases, the adsorption of hydrogen on the Pt atoms on the second layer becomes more favorable (compare adsorption on the $\mathrm{T} 2$ site between $\mathrm{Au}_{81} \mathrm{Pt}_{4}$ and $\mathrm{Pt}_{85} \mathrm{NPs}$ ). Such a trend is also observed in other top sites (e.g., T1 on $\mathrm{Au}_{84} \mathrm{Pt}_{1}-\mathrm{t}$ vs $\mathrm{Pt}_{81} \mathrm{Au}_{4} \mathrm{NPs}$, and T3 on $\mathrm{Pt}_{81} \mathrm{Au}_{4}$ vs $\left.\mathrm{Pt}_{84} \mathrm{Au}_{1}-\mathrm{t} \mathrm{NPs}\right)$. Adsorption on hollow and bridge sites also shows a similar trend. There is only one exception, which is the adsorption on the T4 site. On this site our results suggest that as the number of neighboring $\mathrm{Au}$ atoms increases, the hydrogen adsorption energy becomes less favorable.

Symmetrically, comparing the adsorption energies on the B1 site of $\mathrm{Au}_{85}, \mathrm{Au}_{84} \mathrm{Pt}_{1}-\mathrm{c}$, and $\mathrm{Pt}_{80} \mathrm{Au}_{5} \mathrm{NPs}$, we found that the neighboring $\mathrm{Pt}$ atoms enhance the hydrogen interactions with $\mathrm{Au}$ atoms. However, the effect is not as obvious as the one discussed above. These results suggest that the influence of $\mathrm{Au}$ on the catalytic properties of $\mathrm{Pt}$ is not only due to an ensemble effect, but also a ligand effect. ${ }^{84,85}$ Bus et al. ${ }^{20}$ obtained a similar result experimentally; these authors suggested that $\mathrm{Au}$ might modify the shape of the $5 \mathrm{~d}$ band of neighboring $\mathrm{Pt}$ atoms, yielding higher heat of adsorption for $\mathrm{H}$ on $\mathrm{Pt}$.

Our results show that when the $\mathrm{Au}$ NPs contain small amounts of $\mathrm{Pt}$ (e.g., $\mathrm{Au}_{84} \mathrm{Pt}_{1}-\mathrm{t}, \mathrm{Au}_{80} \mathrm{Pt}_{5}$ and $\mathrm{Au}_{81} \mathrm{Pt}_{4}$ ) hydrogen adsorption becomes much more favorable than on the monometallic Au NP. These results suggest that small amounts of $\mathrm{Pt}$ on $\mathrm{Au}$ NPs could strongly increase their activity toward hydrogen dissociation. Furthermore, in the presence of some neighboring $\mathrm{Pt}$ atoms, we find that hydrogen atoms could adsorb on surface Au sites, which could not happen on the monometallic $\mathrm{Au}_{85} \mathrm{NPs}$. Some experimental results are consistent with our data. For example, Boronat et al. ${ }^{39}$ calculated the adsorption energies of hydrogen atoms on the bridge site of $\mathrm{Au}_{12} \mathrm{Pt}$ and $\mathrm{Au}_{12} \mathrm{Pt} / \mathrm{TiO}_{2}$, obtaining $-32.6 \mathrm{kcal} /$ $\mathrm{mol}$ and $-20.5 \mathrm{kcal} / \mathrm{mol}$, respectively. Serna et al., ${ }^{16}$ e.g., found that the hydrogenation of nitroaromatic compounds catalyzed by $\mathrm{Pt}_{0.01 \%} / \mathrm{Au}_{1.5 \%} / \mathrm{TiO}_{2}$ is 6 times faster than that on $\mathrm{Au} / \mathrm{TiO}_{2}$. Sun et al. ${ }^{15}$ found that the activity of Au catalyst could increase by $1-2$ orders of magnitude by adding widely dispersed $\mathrm{Pt}$.

Electronic Structure Analysis. We discuss some features of the electronic structure of the bare NPs as Supporting Information (Löwdin electronic population, d-band density of states, and charge densities). In what follows, we discuss the electronic features observed on the NPs after hydrogen adsorption. In particular, we highlight changes in charge density and density of states due to hydrogen adsorption.

3.1.3. Electronic Population Analysis. Electronic populations for hydrogen adsorbed on top, bridge, and hollow sites are shown in Tables 4, 5, and 6, respectively. In all cases, we 
Table 4. Electron Population [e] Calculated for the Hydrogen Atom Adsorbed on the Top Sites of the Different NPs Considered in This Work ${ }^{a}$

\begin{tabular}{lcccc} 
& \multicolumn{5}{c}{ electronic population } \\
\cline { 2 - 5 } \multicolumn{1}{c}{$\mathrm{NPs}$} & $\mathrm{T} 1$ & $\mathrm{~T} 2$ & $\mathrm{~T} 3$ & $\mathrm{~T} 4$ \\
$\mathrm{Au}_{85}$ & - & - & - & - \\
$\mathrm{Au}_{84} \mathrm{Pt}_{1}-\mathrm{t}$ & 0.8808 & - & - & - \\
$\mathrm{Au}_{84} \mathrm{Pt}_{1}-\mathrm{c}$ & - & - & - & - \\
$\mathrm{Au}_{81} \mathrm{Pt}_{4}$ & - & 0.8576 & - & - \\
$\mathrm{Au}_{80} \mathrm{Pt}_{5}$ & 0.8951 & 0.8566 & - & - \\
$\mathrm{Pt}_{85}$ & 0.8837 & 0.8542 & 0.8572 & 0.8152 \\
$\mathrm{Pt}_{84} \mathrm{Au}_{1}-\mathrm{t}$ & - & 0.8523 & 0.8573 & 0.8154 \\
$\mathrm{Pt}_{84} \mathrm{Au}_{1}-\mathrm{c}$ & 0.8713 & - & - & 0.8111 \\
$\mathrm{Pt}_{81} \mathrm{Au}_{4}$ & 0.8818 & - & 0.8602 & 0.8224 \\
$\mathrm{Pt}_{80} \mathrm{Au}_{5}$ & - & - & 0.8620 & 0.8242
\end{tabular}

${ }^{a_{\text {The }}}$ symbol "- " indicates that hydrogen adsorption is not favorable on the corresponding site.

Table 5. Electron Population [e] Calculated for the Hydrogen Atom Adsorbed on the Bridge Sites of the Different NPs Considered in This Work ${ }^{a}$

\begin{tabular}{lcccccc} 
& \multicolumn{7}{c}{ electronic } & population \\
\cline { 2 - 7 } \multicolumn{1}{c}{$\mathrm{NPs}$} & $\mathrm{B} 1$ & $\mathrm{~B} 2$ & $\mathrm{~B} 3$ & $\mathrm{~B} 4$ & $\mathrm{~B} 5$ & $\mathrm{~B} 6$ \\
$\mathrm{Au}_{85}$ & 0.9310 & - & - & 0.8994 & - & - \\
$\mathrm{Au}_{84} \mathrm{Pt}_{1}-\mathrm{t}$ & 0.9238 & - & - & 0.9035 & - & - \\
$\mathrm{Au}_{84} \mathrm{Pt}_{1}-\mathrm{c}$ & 0.9364 & - & - & 0.9085 & - & - \\
$\mathrm{Au}_{81} \mathrm{Pt}_{4}$ & 0.8786 & 0.8479 & - & - & - & - \\
$\mathrm{Au}_{80} \mathrm{Pt}_{5}$ & 0.8959 & 0.8343 & - & - & - & - \\
$\mathrm{Pt}_{85}$ & 0.9089 & - & - & 0.8642 & - & 0.8182 \\
$\mathrm{Pt}_{84} \mathrm{Au}_{1}-\mathrm{t}$ & 0.8947 & - & 0.8381 & 0.8637 & - & 0.8193 \\
$\mathrm{Pt}_{84} \mathrm{Au}_{1}-\mathrm{c}$ & 0.9093 & 0.8316 & - & 0.8621 & - & 0.8168 \\
$\mathrm{Pt}_{81} \mathrm{Au}_{4}$ & 0.9316 & - & - & 0.8672 & 0.8358 & - \\
$\mathrm{Pt}_{80} \mathrm{Au}_{5}$ & 0.9373 & - & - & 0.8623 & - & -
\end{tabular}

${ }^{a}$ The symbol "- " indicates that hydrogen adsorption is not favorable on the corresponding site.

Table 6. Electron Population [e] Calculated for the Hydrogen Atom Adsorbed on the Hollow Sites of the Different NPs Considered in This Work ${ }^{a}$

\begin{tabular}{lccccc} 
& \multicolumn{5}{c}{ electronic population [e] } \\
\cline { 2 - 6 } \multicolumn{1}{c}{$\mathrm{NPs}$} & $\mathrm{H} 1$ & $\mathrm{H} 2$ & $\mathrm{H} 3$ & $\mathrm{H} 4$ & $\mathrm{H} 5$ \\
$\mathrm{Au}_{85}$ & - & - & - & - & - \\
$\mathrm{Au}_{84} \mathrm{Pt}_{1}-\mathrm{t}$ & - & - & - & - & - \\
$\mathrm{Au}_{84} \mathrm{Pt}_{1}-\mathrm{c}$ & - & - & - & - & - \\
$\mathrm{Au}_{81} \mathrm{Pt}_{4}$ & - & - & - & - & - \\
$\mathrm{Au}_{80} \mathrm{Pt}_{5}$ & 0.8410 & - & - & - & - \\
$\mathrm{Pt}_{85}$ & 0.8630 & 0.8338 & - & - & 0.8261 \\
$\mathrm{Pt}_{84} \mathrm{Au}_{1}-\mathrm{t}$ & - & 0.8420 & - & - & 0.8260 \\
$\mathrm{Pt}_{84} \mathrm{Au}_{1}-\mathrm{c}$ & 0.8608 & 0.8329 & - & - & 0.8243 \\
$\mathrm{Pt}_{81} \mathrm{Au}_{4}$ & - & - & - & 0.8308 & - \\
$\mathrm{Pt}_{80} \mathrm{Au}_{5}$ & - & - & - & 0.8310 & -
\end{tabular}

${ }^{a}$ The symbol "- " indicates that hydrogen adsorption is not favorable on the corresponding site.

found that the electron count for one hydrogen atom is less than 1 after adsorption, because electrons are transferred to the metal atoms on which adsorption occurs. The extent of electron transfer depends on (1) the position of the adsorbed $\mathrm{H}$; (2) the metal atoms with which $\mathrm{H}$ interacts; and (3) the surrounding metal atoms. More electrons are transferred from
$\mathrm{H}$ when it interacts with $\mathrm{Pt}$ than when it interacts with $\mathrm{Au}$. Hydrogen atoms are more likely to lose electrons when they adsorb on facet sites. For example, the electronic populations of $\mathrm{H}$ atoms adsorbed on the T4 site, $\sim 0.82$, is less than that of $\mathrm{H}$ adsorbed on T1, T2, or T3 sites, 0.85-0.90. Despite these differences, we could not find any correlation between the electron depletion in the adsorbing $\mathrm{H}$ atoms and the adsorption energy.

Probably as a consequence to the electron transfer from the adsorbing hydrogen atoms, significant charge redistribution is observed upon $\mathrm{H}$ adsorption within the NPs. In Table 7, we

Table 7. Electronic Population [e] of the Second Layer Pt Atoms before and after Hydrogen Adsorption on the T2 Site

\begin{tabular}{lcccc} 
& \multicolumn{4}{c}{ electronic population } \\
\cline { 2 - 5 } \multicolumn{1}{c}{$\mathrm{NPs}$} & total & $6 \mathrm{~s}$ & $6 \mathrm{p}$ & $5 \mathrm{~d}$ \\
$\mathrm{Au}_{80} \mathrm{Pt}_{5}$ & 10.1306 & 0.4762 & 0.6899 & 8.9644 \\
$\mathrm{Au}_{80} \mathrm{Pt}_{5} / 2 \mathrm{H}$ & 10.2076 & 0.5484 & 0.8064 & 8.8528 \\
$\mathrm{Au}_{81} \mathrm{Pt}_{4}$ & 10.1844 & 0.4759 & 0.7013 & 9.0072 \\
$\mathrm{Au}_{81} \mathrm{Pt}_{4} / 2 \mathrm{H}$ & 10.2609 & 0.5453 & 0.8250 & 8.8906 \\
$\mathrm{Pt}_{84} \mathrm{Au}_{1}-\mathrm{t}$ & 10.0520 & 0.4929 & 0.6647 & 8.8944 \\
$\mathrm{Pt}_{84} \mathrm{Au}_{1}-\mathrm{t} / 2 \mathrm{H}$ & 10.1428 & 0.5421 & 0.7800 & 8.8240 \\
$\mathrm{Pt}_{85}$ & 10.0056 & 0.4958 & 0.6582 & 8.8516 \\
$\mathrm{Pt}_{85} / 2 \mathrm{H}$ & 10.0999 & 0.5421 & 0.7733 & 8.7846 \\
\hline
\end{tabular}

summarize the electronic population of the second layer $\mathrm{Pt}$ atoms in different NPs before and after hydrogen adsorption. We focus on these atoms because the second layer atoms have most varied local environment (neighboring atoms) within the bimetallic NPs considered here. When adsorbed on the T2 site, one hydrogen atom directly interacts with one metal atom, thus differences in electronic structures will be predominantly due to neighboring atoms. The results show that the electronic population of $\mathrm{Pt}$ atoms increases by $\sim 0.07$ to 0.09 electrons after hydrogen adsorption. The electron accumulation is observed for the most part in s- and p-orbitals, while the electronic population in the $\mathrm{d}$-orbital is reduced by $\sim 0.07$. Our data analysis suggests that the largest the electron depletion from the d-orbitals upon $\mathrm{H}$ adsorption is, the more favorably $\mathrm{H}$ adsorbs on the various sites. It is possible that the $\mathrm{d}$ electrons are delocalized from the $\mathrm{Pt}$ atom to increase the electron density between the $\mathrm{H}-\mathrm{Pt}$ atoms, yielding stronger $\mathrm{H}-\mathrm{Pt}$ bonds. The electron depletion from the d-orbital is observed also when $\mathrm{H}$ directly interacts with two or more metal atoms. Visualization of such phenomena is attempted by analyzing charge density differences, discussed below.

3.1.4. Density of States Analysis of the Hydrogen-Metal Bond. The d-band model, which we invoke in the Supporting Information to qualitatively explain the trends observed for the hydrogen adsorption energies as a function of NPs composition, suggests that adsorption energies and activation barriers mainly depend on the coupling of the hydrogen density of states (H-DOS) to the d-band of metal atoms, which is very sensitive to the transition metals considered. ${ }^{86}$ In Figures 4 and 5, we compare the H-DOS to the d-band structure for several NPs before and after hydrogen adsorption. We also show charge density differences.

In Figure 4, we consider $\mathrm{H}$ adsorbed on the $\mathrm{T} 2$ site of $\mathrm{Pt}_{85}$ and $\mathrm{Au}_{80} \mathrm{Pt}_{5}$ NPs. The DOS of hydrogen atoms is calculated and shown in this figure to analyze $\mathrm{H}-\mathrm{Pt}$ interactions. We found that the d-band structure changes significantly upon $\mathrm{H}$ adsorption on both NPs. Evidence for the mixing between the 

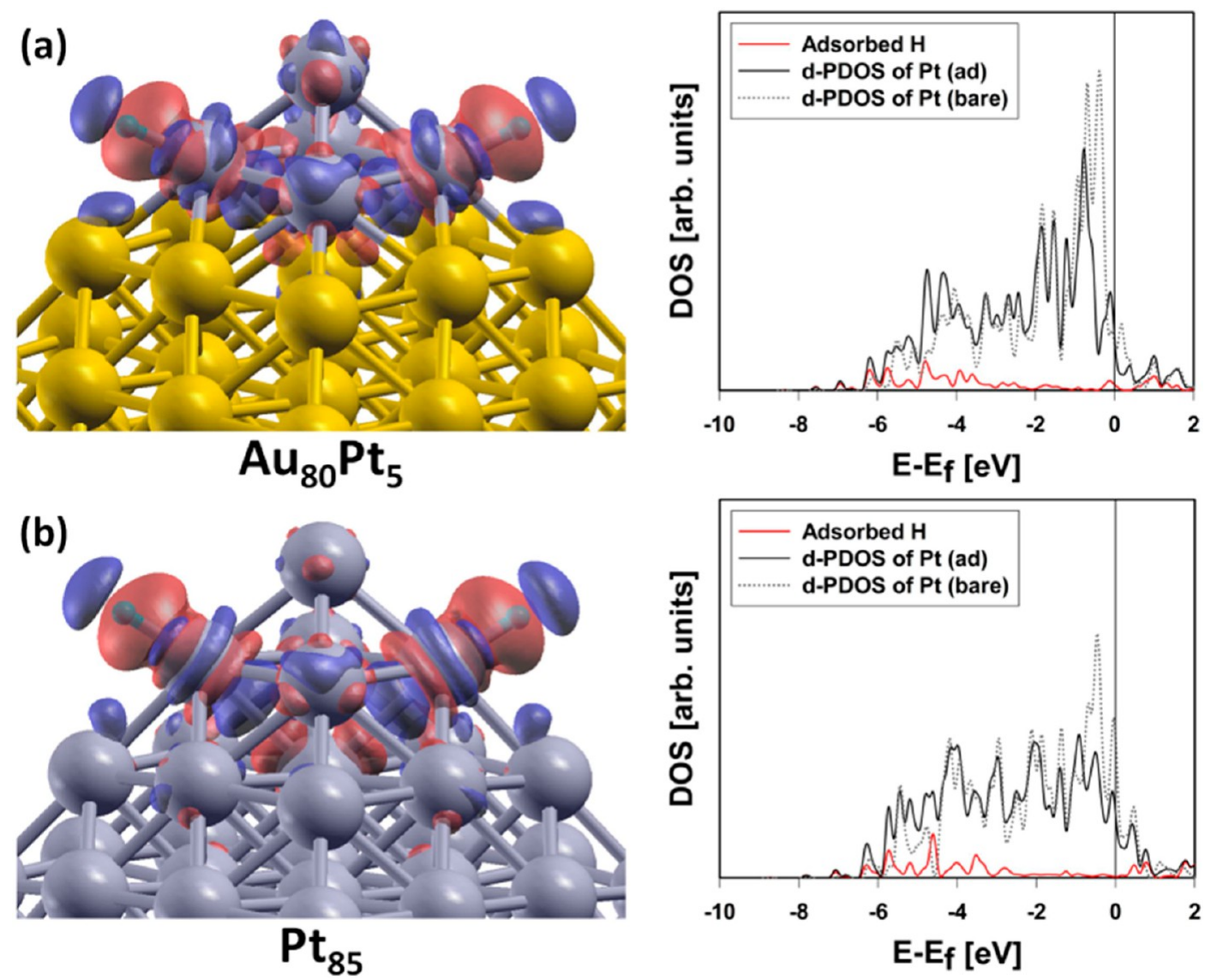

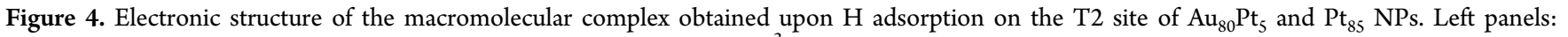
charge density difference plotted at the value of 0.002 electrons/bohr. ${ }^{3}$ Electron accumulation and depletion are represented by blue and red surfaces, respectively. Right panels: density of states of the adsorbed $\mathrm{H}$ atoms (red), and d-PDOS of the second layer atoms before (black dotted) and after (black continuous) hydrogen adsorption. The data on the right panels are obtained for the NPs shown in the left ones.

projected DOS of d orbital (d-PDOS) of Pt and the DOS of $\mathrm{H}$ atom is found within the energy level -3.6 to $-7.0 \mathrm{eV}$ on both NPs, which correspond to the H-metal bonding state. From the d-PDOS of Pt in $\mathrm{Au}_{80} \mathrm{Pt}_{5}$ (see Figure 4a), we found that the peak at ca. $-0.7 \mathrm{eV}$ sharply decreases upon $\mathrm{H}$ adsorption, which suggests electron depletion. On $\mathrm{Pt}_{85}$ (Figure $4 \mathrm{~b}$ ), the electron density at ca. $-0.7 \mathrm{eV}$ also decreases, but not as extensively as in $\mathrm{Au}_{80} \mathrm{Pt}_{5}$. This is due to the modification of the $\mathrm{Pt}$ electronic structure in $\mathrm{Au}_{80} \mathrm{Pt}_{5}$ by the $\mathrm{Au}$ atoms. The electronic density slightly increases at the energy level from -3.6 to $-7.0 \mathrm{eV}$ in both NPs, which indicates electron accumulation, corresponding to the bonding state of $\mathrm{Pt}-\mathrm{H}$. These results indicate that $\mathrm{Pt}$ atoms donate and accept electrons simultaneously upon $\mathrm{H}$ adsorption. Hydrogen adsorption induces more electron depletion from the $\mathrm{Pt} d$ orbital in $\mathrm{Au}_{80} \mathrm{Pt}_{5}$ compared to that in the $\mathrm{Pt}_{85} \mathrm{NP}$, which is consistent with electronic population analysis (see Table 7).

To visualize the DOS, we calculate the charge density difference between the macromolecular complex (two $\mathrm{H}$ atoms adsorbed on the symmetric T2 sites of $\mathrm{Au}_{80} \mathrm{Pt}_{5}$ and $\mathrm{Pt}_{85} \mathrm{NPs}$ ) and the isolated components (NPs and two free $\mathrm{H}$ atoms). The results are shown in Figure 4 (left panels). In all cases, $\mathrm{H}$ atoms donate electrons (as evidenced by the red surface), while electron accumulation localizes on the dumbbell-shaped region near the $\mathrm{Pt}$ atoms, which corresponds to the $\mathrm{Pt} \mathrm{dz}^{2}$ atomic orbital. The electrons depletion from the $\mathrm{Pt} \mathrm{d}$-orbital is also observed (note the two parallel ring-shaped orbitals near $\mathrm{Pt}$, perpendicularly to the $\mathrm{H}-\mathrm{Pt}$ bond). In agreement with the
DOS analysis, the electron depletion is more pronounced in $\mathrm{Au}_{80} \mathrm{Pt}_{5}$ than in $\mathrm{Pt}_{85}$. We also observed charge redistribution on the neighboring metal atoms, which do not directly interact with hydrogen. Although on $\mathrm{Au}_{80} \mathrm{Pt}_{5}$ the neighboring charge redistribution is mostly localized on the $\mathrm{Pt}$ atoms at the second layer, on $\mathrm{Pt}_{85}$ the charge redistribution is observed even on the third and fourth atomic layers. The charge redistribution is much more pronounced on the $\mathrm{Pt}$ atoms in $\mathrm{Au}_{80} \mathrm{Pt}_{5}$ than on $\mathrm{Pt}_{85}$. This indicates that the $\mathrm{Pt}$ atoms in the bimetallic NPs more easily accept and donate electrons than those in the monometallic Pt NP, explaining, in part, why the Pt atoms in the bimetallic NPs are more active toward $\mathrm{H}$ adsorption than those in the monometallic Pt NP (see the T2 site in Table 1).

To study how $\mathrm{H}$ interacts with Au atoms, the electronic structures of $\mathrm{Au}-\mathrm{H}-\mathrm{Au}$ at the $\mathrm{B} 1$ site are characterized and shown in Figure 5. $\mathrm{Au}_{85}$ and $\mathrm{Pt}_{80} \mathrm{Au}_{5}$ NPs are chosen as examples. The d-PDOS of the Au atoms at the second layer before and after $\mathrm{H}$ adsorption are shown in the right panels of Figure 5. Upon $\mathrm{H}$ adsorption, the d-band structure of second layer $\mathrm{Au}$ atoms changes, to some extent, but much less compared to what we just observed on Pt. In Figure 5, several peaks in the d-PDOS at $-5.5 \mathrm{eV}$ to $-9.0 \mathrm{eV}$ appear after $\mathrm{H}$ adsorption. Because these peaks are in common with those of the adsorbed $\mathrm{H}$, they suggest mixing between the d-orbital of $\mathrm{Au}$ and the s-orbital of $\mathrm{H}$.

In Figure $5 b$, we report results obtained for $\mathrm{H}$ adsorption on $\mathrm{Au}_{85}$. Upon hydrogen adsorption, the electron densities in the region from $0 \mathrm{eV}$ to $-2.5 \mathrm{eV}$ decreases (note in particular the 

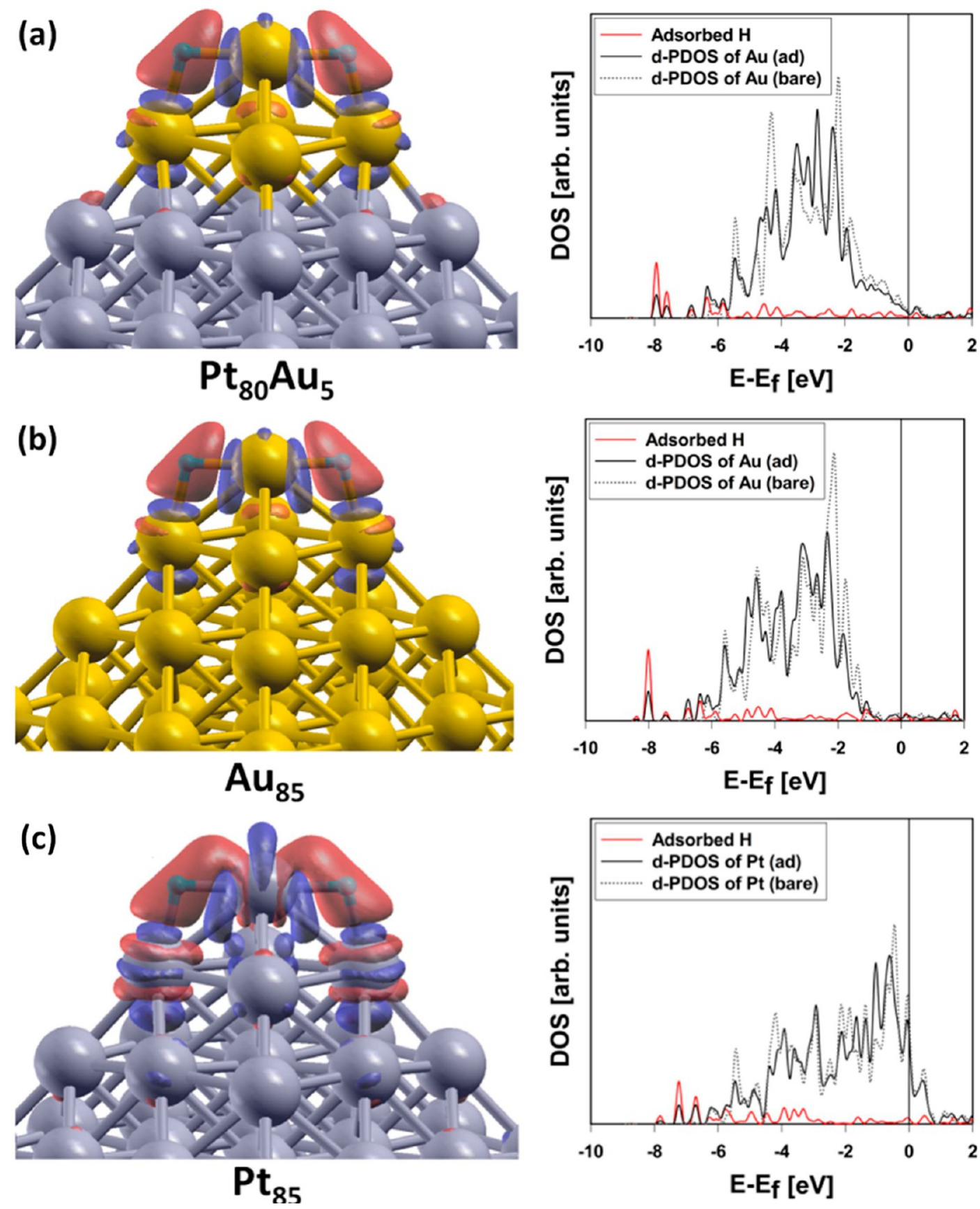

Figure 5. Electronic structure of the macromolecular complex obtained upon $\mathrm{H}$ adsorption on the $\mathrm{B} 1$ site of $\mathrm{Pt}_{80} \mathrm{Au}_{5}, \mathrm{Au}_{85}$, and $\mathrm{Pt}_{85} \mathrm{NPs}_{\mathrm{N}} \mathrm{NPs}$. Left panels: charge density difference plotted at the value of 0.002 electrons/bohr. ${ }^{3}$ Electron accumulation and depletion are represented by blue and red surfaces, respectively. Right panels: density of states of the adsorbed H (red), and d-PDOS of the second layer atoms before (black dotted) and after (black continuous) $\mathrm{H}$ adsorption. The data on the right panels are obtained for the NPs shown in the left ones.

peak at $-2.2 \mathrm{eV})$, indicating electron depletion. Similar changes of the d-band structure are observed when $\mathrm{H}$ adsorbed on $\mathrm{Pt}_{80} \mathrm{Au}_{5}$ (see Figure 5a). Our results suggest that the mechanism of $\mathrm{H}$ interaction with $\mathrm{Au}$ is not significantly affected by the presence of neighboring $\mathrm{Pt}$ atoms in bimetallic NPs, despite the changes reported for the adsorption energies (Table 2). This is due to the d-band of Au being almost filled, and only slightly modified by neighboring Pt atoms. The charge redistribution among the $\mathrm{Au}-\mathrm{H}-\mathrm{Au}$ atomic group on $\mathrm{Au}_{85} \mathrm{NP}$ upon $\mathrm{H}$ adsorption is found to be essentially the same as that observed on the $\mathrm{Pt}_{80} \mathrm{Au}_{5}$ bimetallic NP (see the left panels of Figure 5). In both cases, electrons are donated by $\mathrm{H}$ atoms and accumulate at the $\mathrm{dz}^{2}$ orbital. $\mathrm{Au}$ atoms donate few electrons. For comparison, the electronic structure of the $\mathrm{Pt}-\mathrm{H}-\mathrm{Pt}$ atomic group as observed on the $\mathrm{Pt}_{85} \mathrm{NP}$ is presented in Figure 5c. The results show that the $\mathrm{d}$-band of $\mathrm{Pt}$ is much closer to the Fermi level compared to that of Au. Upon $\mathrm{H}$ adsorption, the peaks in the region from $-6.5 \mathrm{eV}$ to $-8.0 \mathrm{eV}$ provide evidence for the mixing between the $\mathrm{Pt} \mathrm{d}$ - and the $\mathrm{H}$ s- orbitals. After $\mathrm{H}$ adsorption, all the peaks in the Pt d-PDOS decreases, except the one at $\sim-1.06 \mathrm{eV}$, indicating strong electron depletion. In both cases, the electrons are donated by $\mathrm{H}$ atoms and accumulate at the $\mathrm{dz}^{2}$ orbital of the metal atoms. The results indicate that the electron depletion on the $\mathrm{Pt}$ atoms is more 
distinct than that on the $\mathrm{Au}$ atoms, suggesting that the electron depletion from the metal atom is important to explain the strength of the $\mathrm{H}$-metal bond.

Comparing the results shown in Figure 4 to those shown in Figure 5, it appears that charge redistributions within both bimetallic and monometallic NPs are for the most part localized within the atoms that participate to hydrogen adsorption when adsorption occurs on a bridge site, but they can be much delocalized when adsorption occurs on top sites. This probably happens because one $\mathrm{H}$ atom directly binds to two metal atoms on the bridge site, and the two adsorbing metal atoms can share the electrons donated by the hydrogen atom. This might explain why the d-band structure upon $\mathrm{H}$ adsorption does not change as dramatically on the B1 as it does on the T2 sites.

\section{CONCLUSIONS}

We used DFT calculations to study hydrogen atoms adsorption on $\mathrm{Au}, \mathrm{Pt}$, and $\mathrm{Pt}-\mathrm{Au}$ nanoparticles (NPs) composed of 85 atoms. All calculations were focused on the active sites available on one vertex of the NPs. Our results provide mechanistic details concerning how hydrogen interacts with specific metal atoms, which could explain some interesting experimental observations. ${ }^{15,16,38}$ The strongest adsorption can occur when hydrogen interacts with bimetallic NPs rather than pristine Pt NP. When hydrogen atoms adsorb on a gold atom, the $\mathrm{H}-\mathrm{Au}$ bond becomes more energetically favorable when the number of neighboring Pt atoms increases. Perhaps more surprisingly, when hydrogen adsorbs on $\mathrm{Pt}$ our results suggest that the $\mathrm{H}-$ $\mathrm{Pt}$ bond becomes stronger when the number of neighboring $\mathrm{Au}$ atom increases. To interpret our findings, we obtained clues from detailed electronic structure analyses. Both inter- and intra-atomic charge redistributions are observed in $\mathrm{Pt}-\mathrm{Au}$ bimetallic NPs before hydrogen adsorption. The Pt 5d band and the $\mathrm{Au} 5 \mathrm{~d}$ band become narrower and shift to higher energies with respect to the Fermi level compared to results obtained for monometallic NPs. The effect is more pronounced on $\mathrm{Pt}$ than on $\mathrm{Au}$ atoms. In agreement with the d-band model, our results suggest that the higher the d-band center, the stronger the hydrogen adsorption. Perhaps more interestingly, however, our results reveal that electrons are donated by both hydrogen and metal atoms upon hydrogen adsorption. More electrons are donated by $\mathrm{Pt}$ than by $\mathrm{Au}$. Pt atoms in bimetallic NPs sometimes more easily donate and accept electrons than those in monometallic Pt NPs, which might have important consequences in the design of bimetallic catalysts for hydrogenation reactions.

\section{ASSOCIATED CONTENT}

\section{S Supporting Information}

Additional results obtained when a hydrogen atom adsorbs on $\mathrm{Au}_{79} \mathrm{Pt}_{6}$ and $\mathrm{Pt}_{79} \mathrm{Au}_{6}$ (in these NPs all vertex atoms of $\mathrm{Au}_{85}$ and $\mathrm{Pt}_{85}$ are replaced with the second metal); additional calculations conducted to assess the interactions between two adsorbed hydrogen atoms; additional results concerning the electronic properties of bare NPs, including electronic population, d-band DOS, and highest occupied molecular orbitals. This material is available free of charge via the Internet at http://pubs.acs.org.

\section{AUTHOR INFORMATION}

\section{Corresponding Author}

*E-mail: astriolo@ou.edu.

\section{Notes}

The authors declare no competing financial interest.

\section{ACKNOWLEDGMENTS}

This work was supported, in part, by the U.S. Department of Energy, via CANTEC, the Carbon Nanotubes Technology Center at the University of Oklahoma. A.S. and D.P.L. are grateful to an ROA summer fellowship from the Oklahoma EPSCoR program, supported by the U.S. National Science Foundation. Generous allocations of computing time were provided by the Oklahoma Supercomputer Center for Education and Research (OSCER) and by the National Energy Research Scientific Computing Center (NERSC). NERSC is supported by the Office of Science of the U.S. Department of Energy under Contract No. DE-AC02-05CH11231. The authors wish to thank Profs. Friederike Jentoft, Richard Mallinson, and Daniel Resasco of the University of Oklahoma for insightful discussions.

\section{REFERENCES}

(1) Hammer, B.; Norskov, J. K. Why gold is the noblest of all the metals. Nature 1995, 376 (6537), 238-240.

(2) Bond, G. C.; Thompson, D. T. Catalysis by gold. Catal. Rev.-Sci. Eng. 1999, 41 (3-4), 319-388.

(3) Haruta, M. Catalysis of gold nanoparticles deposited on metal oxides. CATTECH 2002, 6 (3), 102-115.

(4) Mohr, C.; Hofmeister, H.; Radnik, J.; Claus, P. Identification of active sites in gold-catalyzed hydrogenation of acrolein. J. Am. Chem. Soc. 2003, 125 (7), 1905-1911.

(5) Lee, S. S.; Fan, C. Y.; Wu, T. P.; Anderson, S. L. CO oxidation on $\mathrm{Au}_{n} / \mathrm{TiO}_{2}$ catalysts produced by size-selected cluster deposition. J. Am. Chem. Soc. 2004, 126 (18), 5682-5683.

(6) Haruta, M. Size- and support-dependency in the catalysis of gold. Catal. Today 1997, 36 (1), 153-166.

(7) Haruta, M.; Date, M. Advances in the catalysis of $\mathrm{Au}$ nanoparticles. Appl. Catal., A 2001, 222 (1-2), 427-437.

(8) Deng, W. L.; Flytzani-Stephanopoulos, M. On the issue of the deactivation of Au-ceria and Pt-ceria water-gas shift catalysts in practical fuel-cell applications. Angew. Chem., Int. Ed. 2006, 45 (14), 2285-2289.

(9) Hugon, A.; Delannoy, L.; Louis, C. Supported gold catalysts for selective hydrogenation of 1,3-butadiene in the presence of an excess of alkenes. Gold Bull. 2008, 41 (2), 127-138.

(10) Corma, A.; Serna, P. Chemoselective hydrogenation of nitro compounds with supported gold catalysts. Science 2006, 313 (5785), 332-334.

(11) Kartusch, C.; Bokhoven, J. A. Hydrogenation over gold catalysts: The interaction of gold with hydrogen. Gold Bull. 2009, 42 (4), 343-347.

(12) Englisch, M.; Jentys, A.; Lercher, J. A. Structure sensitivity of the hydrogenation of crotonaldehyde over $\mathrm{Pt} / \mathrm{SiO}_{2}$ and $\mathrm{Pt} / \mathrm{TiO}_{2}$. J. Catal. 1997, 166 (1), 25-35.

(13) Zanella, R.; Louis, C.; Giorgio, S.; Touroude, R. Crotonaldehyde hydrogenation by gold supported on $\mathrm{TiO}_{2}$ : Structure sensitivity and mechanism. J. Catal. 2004, 223 (2), 328-339.

(14) Buchanan, D. A.; Webb, G. Catalysis by group IB metals 0.1. Reaction of buta-1,3-diene with hydrogen and with deuterium catalyzed by alumina-supported gold. J. Chem. Soc., Faraday Trans. 1 1975, 71 (1), 134-144.

(15) Sun, K. Q.; Hong, Y. C.; Zhang, G. R.; Xu, B. Q. Synergy between $\mathrm{Pt}$ and $\mathrm{Au}$ in Pt-on-Au nanostructures for chemoselective hydrogenation catalysis. ACS Catal. 2011, 1 (10), 1336-1346.

(16) Serna, P.; Concepcion, P.; Corma, A. Design of highly active and chemoselective bimetallic gold-platinum hydrogenation catalysts through kinetic and isotopic studies. J. Catal. 2009, 265 (1), 19-25. 
(17) Barton, D. G.; Podkolzin, S. G. Kinetic study of a direct water synthesis over silica-supported gold nanoparticles. J. Phys. Chem. B 2005, 109 (6), 2262-2274.

(18) Lin, S.; Vannice, M. A. Gold dispersed on $\mathrm{TiO}_{2}$ and $\mathrm{SiO}_{2}$ Adsorption properties and catalytic behavior in hydrogenation reactions. Catal. Lett. 1991, 10 (1-2), 47-62.

(19) Bus, E.; Miller, J. T.; van Bokhoven, J. A. Hydrogen chemisorption on $\mathrm{Al}_{2} \mathrm{O}_{3}$-supported gold catalysts. J. Phys. Chem. $B$ 2005, 109 (30), 14581-14587.

(20) Bus, E.; van Bokhoven, J. A. Hydrogen chemisorption on supported platinum, gold, and platinum-gold-alloy catalysts. Phys. Chem. Chem. Phys. 2007, 9 (22), 2894-2902.

(21) Fujitani, T.; Nakamura, I.; Akita, T.; Okumura, M.; Haruta, M. Hydrogen Dissociation by Gold Clusters. Angew. Chem., Int. Ed. 2009, 48 (50), 9515-9518.

(22) Boronat, M.; Illas, F.; Corma, A. Active sites for $\mathrm{H}_{2}$ adsorption and activation in $\mathrm{Au} / \mathrm{TiO}_{2}$ and the role of the support. J. Phys. Chem. A 2009, 113 (16), 3750-3757.

(23) Barrio, L.; Liu, P.; Rodriguez, J. A.; Campos-Martin, J. M.; Fierro, J. L. G., A density functional theory study of the dissociation of $\mathrm{H}_{2}$ on gold clusters: Importance of fluxionality and ensemble effects. $J$. Chem. Phys. 2006, 125 (16).

(24) Christmann, K. Interaction of hydrogen with solid-surfaces. Surf. Sci. Rep. 1988, 9 (1-3), 1-163.

(25) Oudenhuijzen, M. K.; van Bokhoven, J. A.; Miller, J. T.; Ramaker, D. E.; Koningsberger, D. C. Three-site model for hydrogen adsorption on supported platinum particles: Influence of support ionicity and particle size on the hydrogen coverage. J. Am. Chem. Soc. 2005, 127 (5), 1530-1540.

(26) Zhou, C. G.; Wu, J. P.; Nie, A. H.; Forrey, R. C.; Tachibana, A.; Cheng, H. S. On the sequential hydrogen dissociative chemisorption on small platinum clusters: A density functional theory study. J. Phys. Chem. C 2007, 111 (34), 12773-12778.

(27) Bernasek, S. L.; Somorjai, G. A. Molecular-beam study of mechanism of catalyzed hydrogen-deuterium exchange on platinum single-crystal surfaces. J. Chem. Phys. 1975, 62 (8), 3149-3161.

(28) Li, Y. M.; Somorjai, G. A. Nanoscale advances in catalysis and energy applications. Nano Lett. 2010, 10 (7), 2289-2295.

(29) Markovic, N. M.; Schmidt, T. J.; Stamenkovic, V.; Ross, P. N. Oxygen reduction reaction on $\mathrm{Pt}$ and $\mathrm{Pt}$ bimetallic surfaces: A selective review. Fuel Cells 2001, 1 (2), 105-116.

(30) Zhao, D.; Xu, B. Q. Enhancement of Pt utilization in electrocatalysts by using gold nanoparticles. Angew. Chem., Int. Ed. 2006, 45 (30), 4955-4959.

(31) Luo, J.; Njoki, P. N.; Lin, Y.; Mott, D.; Wang, L. Y.; Zhong, C. J. Characterization of carbon-supported AuPt nanoparticles for electrocatalytic methanol oxidation reaction. Langmuir 2006, 22 (6), 28922898.

(32) Choi, J. H.; Jeong, K. J.; Dong, Y.; Han, J.; Lim, T. H.; Lee, J. S.; Sung, Y. E. Electro-oxidation of methanol and formic acid on PtRu and PtAu for direct liquid fuel cells. J. Power Sources 2006, 163 (1), 71-75.

(33) Zhao, D.; Wang, Y. H.; Xu, B. Q. Pt flecks on colloidal Au $(\mathrm{Pt} \wedge \mathrm{Au})$ as nanostructured anode catalysts for electrooxidation of formic acid. J. Phys. Chem. C 2009, 113 (49), 20903-20911.

(34) Xu, J. B.; Zhao, T. S.; Liang, Z. X. Carbon supported platinumgold alloy catalyst for direct formic acid fuel cells. J. Power Sources 2008, 185 (2), 857-861.

(35) Kyriakou, G.; Boucher, M. B.; Jewell, A. D.; Lewis, E. A.; Lawton, T. J.; Baber, A. E.; Tierney, H. L.; Flytzani-Stephanopoulos, M.; Sykes, E. C. H. Isolated metal atom geometries as a strategy for selective heterogeneous hydrogenations. Science 2012, 335 (6073), 1209-1212.

(36) Jiang, K.; Zhang, H.-X.; Yang, Y.-Y.; Mothes, R.; Lang, H.; Cai, W.-B. Facile synthesis of $\mathrm{Ag} @ \mathrm{Pd}$ satellites-Fe3O4 core nanocomposites as efficient and reusable hydrogenation catalysts. Chem. Commun. 2011, 47 (43), 11924-11926.

(37) González, S.; Neyman, K. M.; Shaikhutdinov, S.; Freund, H.-J.; Illas, F. On the Promoting Role of $\mathrm{Ag}$ in Selective Hydrogenation
Reactions over Pd-Ag Bimetallic Catalysts: A Theoretical Study. J. Phys. Chem. C 2007, 111 (18), 6852-6856.

(38) Hong, Y. C.; Sun, K. Q.; Zhang, G. R.; Zhong, R. Y.; Xu, Q. Fully dispersed $\mathrm{Pt}$ entities on nano-Au dramatically enhance the activity of gold for chemoselective hydrogenation catalysis. Chem. Commun. 2011, 47 (4), 1300-1302.

(39) Boronat, M.; Corma, A. Origin of the different activity and selectivity toward hydrogenation of single metal $\mathrm{Au}$ and $\mathrm{Pt}$ on $\mathrm{TiO}_{2}$ and bimetallic $\mathrm{Au}-\mathrm{Pt} / \mathrm{TiO}_{2}$ Catalysts. Langmuir 2010, 26 (21), 16607-16614.

(40) Massalski, T. B.; Okamoto, H. Binary Alloy Phase Diagrams, 2nd ed.; ASM International: Materials Park, OH, 1990.

(41) Braidy, N.; Purdy, G. R.; Botton, G. A. Equilibrium and stability of phase-separating Au-Pt nanoparticles. Acta Mater. 2008, 56 (20), 5972-5983.

(42) Wanjala, B. N.; Luo, J.; Fang, B.; Mott, D.; Zhong, C. J. Goldplatinum nanoparticles: Alloying and phase segregation. J. Mater. Chem. 2011, 21 (12), 4012-4020.

(43) Luo, J.; Maye, M. M.; Petkov, V.; Kariuki, N. N.; Wang, L. Y.; Njoki, P.; Mott, D.; Lln, Y.; Zhong, C. J. Phase properties of carbonsupported gold-platinum nanoparticles with different bimetallic compositions. Chem. Mater. 2005, 17 (12), 3086-3091.

(44) Schrinner, M.; Proch, S.; Mei, Y.; Kempe, R.; Miyajima, N.; Ballauff, M. Stable bimetallic gold-platinum nanoparticles immobilized on spherical polyelectrolyte brushes: Synthesis, characterization, and application for the oxidation of alcohols. Adv. Mater. 2008, 20 (10), 1928.

(45) Zhou, S. H.; Jackson, G. S.; Eichhorn, B. AuPt alloy nanoparticles for CO-tolerant hydrogen activation: Architectural effects in $\mathrm{Au}-\mathrm{Pt}$ bimetallic nanocatalysts. Adv. Funct. Mater. 2007, 17 (16), 3099-3104.

(46) Malis, O.; Radu, M.; Mott, D.; Wanjala, B.; Luo, J.; Zhong, C. J., $\mathrm{An}$ in situ real-time X-ray diffraction study of phase segregation in $\mathrm{Au}-$ Pt nanoparticles. Nanotechnology 2009, 20 (24).

(47) Yang, Z.; Yang, X. N.; Xu, Z. J.; Liu, S. Y. Structural evolution of $\mathrm{Pt}-\mathrm{Au}$ nanoalloys during heating process: Comparison of random and core-shell orderings. Phys. Chem. Chem. Phys. 2009, 11 (29), 62496255.

(48) Morrow, B. H.; Striolo, A., Supported bimetallic Pt-Au nanoparticles: Structural features predicted by molecular dynamics simulations. Phys. Rev. B 2010, 81 (15).

(49) Xiao, S.; Hu, W.; Luo, W.; Wu, Y.; Li, X.; Deng, H. Size effect on alloying ability and phase stability of immiscible bimetallic nanoparticles. Eur. Phys. J. B 2006, 54 (4), 479-484.

(50) Yang, J.; Lee, J. Y.; Too, H. P. Phase-transfer identification of core-shell structures in bimetallic nanoparticles. Plasmonics 2006, 1 (1), 67-78.

(51) Liu, H. B.; Pal, U.; Ascencio, J. A. Thermodynamic stability and melting mechanism of bimetallic Au-Pt nanoparticles. J. Phys. Chem. C 2008, 112 (49), 19173-19177.

(52) Kitchin, J. R.; Norskov, J. K.; Barteau, M. A.; Chen, J. G. Modification of the surface electronic and chemical properties of $\mathrm{Pt}$ (111) by subsurface 3d transition metals. J. Chem. Phys. 2004, 120 (21), 10240-10246.

(53) Hammer, B.; Norskov, J. K. Electronic factors determining the reactivity of metal surfaces. Surf. Sci. 1995, 343 (3), 211-220.

(54) Kokalj, A., Computer graphics and graphical user interfaces as tools in simulations of matter at the atomic scale. Comput. Mater. Sci. 2003, 28.

(55) Okamoto, Y. Comparison of hydrogen atom adsorption on $\mathrm{Pt}$ clusters with that on Pt surfaces: A study from density-functional calculations. Chem. Phys. Lett. 2006, 429 (1-3), 209-213.

(56) Bus, E.; van Bokhoven, J. A. Electronic and geometric structures of supported platinum, gold, and platinum-gold catalysts. J. Phys. Chem. C 2007, 111 (27), 9761-9768.

(57) Wang, L. L.; Johnson, D. D. Density functional study of structural trends for late-transition-metal 13-atom clusters. Phys. Rev. B 2007, 75 (23), 235405. 
(58) Xiao, L.; Wang, L. C. Structures of platinum clusters: Planar or spherical? J. Phys. Chem. A 2004, 108 (41), 8605-8614.

(59) Kumar, V.; Kawazoe, Y., Evolution of atomic and electronic structure of Pt clusters: Planar, layered, pyramidal, cage, cubic, and octahedral growth. Phys. Rev. B 2008, 77 (20).

(60) Jellinek, J.; Krissinel, E. B. NinAlm alloy clusters: Analysis of structural forms and their energy ordering. Chem. Phys. Lett. 1996, 258 (1-2), 283-292.

(61) Cleveland, C. L.; Landman, U.; Shafigullin, M. N.; Stephens, P. W.; Whetten, R. L. Structural evolution of larger gold clusters. Z. Phys. D: At., Mol. Clusters 1997, 40 (1-4), 503-508.

(62) Barnard, A. S.; Curtiss, L. A. Predicting the shape and structure of face-centered cubic gold nanocrystals smaller than $3 \mathrm{~nm}$. ChemPhysChem 2006, 7 (7), 1544-1553.

(63) Giannozzi, P.; Baroni, S.; Bonini, N.; Calandra, M.; Car, R.; Cavazzoni, C.; Ceresoli, D.; Chiarotti, G. L.; Cococcioni, M.; Dabo, I.; Dal Corso, A.; de Gironcoli, S.; Fabris, S.; Fratesi, G.; Gebauer, R.; Gerstmann, U.; Gougoussis, C.; Kokalj, A.; Lazzeri, M.; Martin-Samos, L.; Marzari, N.; Mauri, F.; Mazzarello, R.; Paolini, S.; Pasquarello, A.; Paulatto, L.; Sbraccia, C.; Scandolo, S.; Sclauzero, G.; Seitsonen, A. P.; Smogunov, A.; Umari, P.; Wentzcovitch, R. M. QUANTUM ESPRESSO: A modular and open-source software project for quantum simulations of materials. J. Phys.: Condens. Matter 2009, 21 (39), 395502.

(64) Perdew, J. P.; Burke, K.; Ernzerhof, M. Generalized gradient approximation made simple. Phys. Rev. Lett. 1996, 77 (18), 38653868.

(65) Vanderbilt, D. Soft self-consistent pseudopotentials in a generalized eigenvalue formalism. Phys. Rev. B 1990, 41 (11), 78927895.

(66) Rappe, A. M.; Rabe, K. M.; Kaxiras, E.; Joannopoulos, J. D. Optimized pseudopotentials. Phys. Rev. B 1990, 41 (2), 1227-1230.

(67) Camellone, M. F.; Fabris, S. Reaction mechanisms for the CO oxidation on $\mathrm{Au} / \mathrm{CeO}_{2}$ catalysts: Activity of substitutional $\mathrm{Au}^{3+} / \mathrm{Au}^{+}$ cations and deactivation of supported $\mathrm{Au}^{+}$adatoms. J. Am. Chem. Soc. 2009, 131 (30), 10473-10483.

(68) Lowdin, P. O. On the non-orthogonality problem connected with the use of atomic wave functions in the theory of molecules and crystals. J. Chem. Phys. 1950, 18 (3), 365-375.

(69) Tran, D. T.; Johnston, R. L. Study of 40-atom Pt-Au clusters using a combined empirical potential-density functional approach. Proc. R. Soc., Ser. A 2011, 467 (2131), 2004-2019.

(70) Leppert, L.; Kummel, S. The electronic structure of goldplatinum nanoparticles: Collecting clues for why they are special. $J$. Phys. Chem. C 2011, 115 (14), 6694-6702.

(71) Deng, L.; Hu, W. Y.; Deng, H. Q.; Xiao, S. F. Surface segregation and structural features of bimetallic $\mathrm{Au}-\mathrm{Pt}$ nanoparticles. J. Phys. Chem. C 2010, 114 (25), 11026-11032.

(72) Henglein, A. Preparation and optical aborption spectra of $\mathrm{Au}_{\text {core }} \mathrm{Pt}_{\text {shell }}$ and $\mathrm{Pt}_{\text {core }} \mathrm{Au}_{\text {shell }}$ colloidal nanoparticles in aqueous solution (vol 104B, pg 2201, 2000). J. Phys. Chem. B 2000, 104 (10), 24322432.

(73) Hodak, J. H.; Henglein, A.; Hartland, G. V. Tuning the spectral and temporal response in PtAu core-shell nanoparticles. J. Chem. Phys. 2001, 114 (6), 2760-2765.

(74) Ferrando, R; Fortunelli, A.; Johnston, R. L. Searching for the optimum structures of alloy nanoclusters. Phys. Chem. Chem. Phys. 2008, 10 (5), 640-649.

(75) Crljen, Z.; Lazic, P.; Sokcevic, D.; Brako, R. Relaxation and reconstruction on (111) surfaces of $\mathrm{Au}, \mathrm{Pt}$, and $\mathrm{Cu}$. Phys. Rev. B 2003, 68 (19).

(76) Varganov, S. A.; Olson, R. M.; Gordon, M. S.; Mills, G.; Metiu, H. A study of the reactions of molecular hydrogen with small gold clusters. J. Chem. Phys. 2004, 120 (11), 5169-5175.

(77) Cui, Q.; Musaev, D. G.; Morokuma, K. Molecular orbital study of $\mathrm{H}_{2}$ and $\mathrm{CH}_{4}$ activation on small metal clusters. 2. $\mathrm{Pd}_{3}$ and $\mathrm{Pt}_{3}$. J. Phys. Chem. A 1998, 102 (31), 6373-6384.

(78) Liu, X.; Dilger, H.; Eichel, R. A.; Kunstmann, J.; Roduner, E. A small paramagnetic platinum cluster in an $\mathrm{NaY}$ zeolite: Character- ization and hydrogen adsorption and desorption. J. Phys. Chem. B 2006, 110 (5), 2013-2023.

(79) Verheij, L. K.; Hugenschmidt, M. B. Hydrogen adsorption on oxygen-covered Pt(111). Surf. Sci. 1995, 324 (2-3), 185-201.

(80) Verheij, L. K.; Hugenschmidt, M. B.; Anton, A. B.; Poelsema, B.; Comsa, G. A molecular-beam study of the interaction between hydrogen and the $\mathrm{Pt}(111)$ surface. Surf. Sci. 1989, 210 (1-2), 1-26.

(81) Nieuwenhuys, B. E. Influence of surface-structure on adsorption of hydrogen on platinum, as studied by field-emission probe-hole microscopy. Surf. Sci. 1976, 59 (2), 430-446.

(82) Balakrishnan, K.; Sachdev, A.; Schwank, L. Chemisorption and FTIR study of bimetallic $\mathrm{Pt}-\mathrm{Au} / \mathrm{SiO}_{2}$ catalysts. J. Catal. 1990, 121 (2), 441-455.

(83) Chandler, B. D.; Pignolet, L. H. DRIFTS studies of carbon monoxide coverage on highly dispersed bimetallic $\mathrm{Pt}-\mathrm{Cu}$ and $\mathrm{Pt}-\mathrm{An}$ catalysts. Catal. Today 2001, 65 (1), 39-50.

(84) Parsons, R.; Sachtler, W. M.; Gerische., H.; Feil, D.; Vanderav., A.; Dehempti., X. Discussion of role individual surface atoms in chemisorption and catalysis by nickel-copper alloys. Surf. Sci. 1969, 18 (1), 77.

(85) Sachtler, W. M. Surface composition of alloys in equilibrium. Vide: Sci., Tech. Appl. 1973, 28 (164), 67-71.

(86) Bligaard, T.; Norskov, J. K. Ligand effects in heterogeneous catalysis and electrochemistry. Electrochim. Acta 2007, 52 (18), 55125516. 